\title{
DETECÇÃO AUTOMÁTICA DE NUVEM E SOMBRA DE NUVEM EM IMAGENS DE SENSORIAMENTO REMOTO
}

\author{
Automatic detection of cloud and cloud shadow in remote sensing images
}

\author{
Marco Aurélio Oliveira da Silva ${ }^{1}$ \\ Frederico dos Santos Liporace ${ }^{2}$ \\ ${ }^{1}$ AMS Kepler Engenharia de Sistemas, Avenida Armando Lombardi, 800, sala 206, Barra da Tijuca - \\ 22640-020 - Rio de Janeiro, RJ \\ ${ }^{2}$ AMS Kepler Engenharia de Sistemas, Rua Alfredo Nogueira Ignácio Penido, 300, sala 58 - 12246-000 - \\ São José dos Campos, SP
}

\section{Resumo:}

Nesse trabalho é apresentada uma metodologia para a detecção automática de nuvem e sombra de nuvem em imagens de sensores que atuam na faixa do visível e do infravermelho próximo. $\mathrm{O}$ trabalho visa à detecção em imagens do sensor AWFI que estará a bordo do satélite AMAZONIA1. O método de detecção de nuvem baseia-se na aplicação de três filtros. Valores de NDVI, WI e HOT, calculados a partir das reflectâncias das bandas espectrais, são usados na detecção. A detecção de sombra de nuvem é feita a partir da integração das máscaras de pixeis escuros e água com a imagem resultante da diferença entre a cena a ser classificada e uma referência da mesma região, idealmente sem nuvens e bem registrada. Na inexistência de imagens AWFI, visto que o satélite se encontra em fase de construção, os testes foram conduzidos com imagens LANDSAT5 TM. A acurácia média da classificação de nuvem foi de $88.70 \%$ e da classificação de sombra de nuvem de $75.03 \%$. A acurácia global da classificação mostrou que mais de $90 \%$ dos pixeis das imagens problemáticas selecionadas para o teste foram classificados corretamente como nuvem, não nuvem, sombra e não sombra.

Palavras-chave: detecção automática, nuvem, sombra de nuvem, reflectância, AWFI, AMAZONIA-1.

\begin{abstract}
:
This paper presents an automatic method to detect cloud and cloud shadow in remote sensing images that works in visible and near infrared spectrum. The aim of the paper is the detection in AWFI images of the AMAZONIA-1 satellite. The cloud detection is based on applying three filters. The reflectance of spectral bands is used to compute the NDVI, WI and HOT values used by classifier. The cloud shadow detection is done by integration of dark pixels and water masks with the image resulting from difference between the scene to be classified and a reference of the same region, ideally free cloud and perfectly registered. In the absence of AWFI images, since the AMAZONIA-1 satellite is still in construction phase, the tests have been done with LANDSAT-5 TM images. The mean accuracy of cloud detection is $88.70 \%$ and of cloud shadow detection is
\end{abstract}


$75.03 \%$. The global accuracy of classification has shown that over $90 \%$ of the pixels have been classified correctly as cloud, no cloud, no shade and shadow.

Keywords: automatic detection, cloud, cloud shadow, reflectance, AWFI, AMAZONIA-1.

\section{Introdução}

A presença de nuvens e sombras é inevitável em imagens de sensores remoto óptico. Além do problema de oclusão de feições que reduz a área útil da imagem, causado pela nuvem e pela projeção de sua sombra no terreno, existe a interferência na análise quantitativa da imagem. Nesse caso, pixeis interferidos por nuvem e sombra são tratados como pixeis válidos e contaminam os valores calculados.

Em um primeiro instante detectar nuvem e sombra parece ser uma tarefa simples. Nuvem apresenta uma alta resposta na região do visível e infravermelho próximo. Sombra de nuvem é iluminada predominantemente por energia espalhada (Zhu e Woodcock, 2011). Assim, espera-se na imagem por nuvem branca e sombra escura. Isso é valido para tipos específicos de nuvens. Porém, nuvem nem sempre é branca e sombra nem sempre é a feição mais escura da imagem. Isso explica o fato de métodos baseados apenas em limiares funcionarem bem em algumas imagens e em outras não. O problema é mais complexo e exige algoritmos mais sofisticados que levem em conta as propriedades físicas das feições.

Encontram-se na literatura diversas metodologias para detecção de nuvem e sombra de nuvem seguindo diferentes abordagens. Na seção 2 apresentam-se resumidamente algumas dessas metodologias. De uma forma geral as metodologias baseadas em limiares são usadas para detectar nuvem e sombra de forma grosseira. As feições detectadas inicialmente são refinadas nos processamentos posteriores (Silva et al., 2007; Li et al., 2004). Na existência de imagens multitemporais, uma análise da pirâmide pode ser feita para reduzir a quantidade de dados a serem processados (Champion, 2012; Song e Civco, 2002). A geometria de visada do sensor e de iluminação solar permite correlacionar nuvem e sombra (Silva et al., 2007; Li et al., 2004; Zhu e Woodcock, 2011). A banda termal é uma fonte importantíssima de informação na detecção desse tipo de feição. A ausência dessa banda dificulta ainda mais esse tipo de processamento.

Nesse trabalho é apresentado um detector automático de nuvem e sombra de nuvem para imagens de sensores que atuam na faixa do visível e do infravermelho próximo. A adoção dessa faixa do espectro eletromagnético se deve ao fato do trabalho visar à detecção de nuvem e sombra de nuvem em imagens do sensor AWFI (Advanced Wide Field Imager Camera) que estará a bordo do satélite AMAZONIA-1. A detecção de nuvem baseia-se na solução proposta por Zhu e Woodcock (2011). A sombra de nuvem é obtida da integração das máscaras de pixeis escuros e água com a imagem diferença.

Esse trabalho está inserido num problema maior que é a geração automática de mosaicos multitemporais livre de interferências por nuvem ou sombra de nuvem para imagens AWFI.

$\mathrm{Na}$ inexistência de imagens AMAZONIA-1 AWFI, visto que o satélite se encontra em fase de construção, os testes foram conduzidos com imagens LANDSAT-5 TM.

A seção 2 apresenta alguns trabalhos relacionados com a detecção de nuvem e sombra. As características da câmera AWFI são apresentadas brevemente na seção 3. A metodologia proposta 
para detecção de nuvem e sombra é apresentada na seção 4. Os resultados e as discussões são apresentados na seção 5. Na seção 6 são apresentadas as principais conclusões.

\section{Trabalhos Prévios}

Polidorio et al. (2006) apresenta uma técnica para segmentação de corpos d'água, nuvens e sombras em imagens multiespectrais adquiridas pelos satélites CBERS e LANDSAT. A técnica proposta baseia-se apenas nos dados espectrais das feições imageadas. A detecção e a discriminação são feitas a partir dos índices Normalized Difference Vegetation Index (NDVI), Weighted Water Index (WWI) e componentes intensidade (I) e saturação (S) do sistema HSI (Hue, Saturation, Intensity). O método é dividido em duas partes. Na primeira é feita a detecção das nuvens, sombras e água. A segunda parte consiste num ajuste radiométrico que minimiza os efeitos causados pelo espalhamento e absorção atmosférica. A partir do NDVI, WWI, I, S e do ND do pixel o autor define um modelo matemático e algumas regras para classificar os pixeis como nuvem, sombra ou água. Os pixeis de nuvem e de sombra são usados num método de ajuste radiométrico que permite melhorar o contraste entre as feições. A imagem resultante desse processo é submetida novamente ao método de detecção, permitindo resultados mais precisos. A segmentação de nuvens falha quando nuvens pouco densas estão sobre corpos d'água, as quais são freqüentemente confundidas com sombra devido à mistura espectral. Nuvens também são confundidas com feições de altíssima reflectância. Na segmentação de sombras, as transições entre corpos d'água e vegetação e entre corpos d'água e nuvens são facilmente confundidas com sombra. O método consegue discriminar entre regiões de sombras e corpos d'água, mesmo quando esses dois elementos estão conectados.

Silva et al. (2007) apresenta uma técnica para correlacionar nuvens e sombras. A metodologia apresentada é voltada para imagens do sensor CCD a bordo do satélite CBERS. Segundo o autor, a correlação nuvem/sombra é indicada para a detecção de nuvens de baixa altitude, tais como nuvens do tipo Cumulus e Stratocumulus que apresentam sombras possíveis de detectar e, normalmente, ocupam pequenas áreas. $\mathrm{O}$ autor sugere um método paramétrico relaxado para detectar o maior número possível de candidatos a nuvens e sombras. As potenciais nuvens são extraídas a partir das bandas 1, 2, 3 e 4. Para identificação das sombras são usadas as bandas 2 e 4. A correlação nuvem/sombra é feita em duas etapas. Na primeira são feitas restrições geométricas sobre os pontos candidatos a sombra com base na localização e na área das sombras projetadas pelos pontos candidatos a nuvens. O objetivo aqui é confirmar os pixeis da classe sombra. A segunda etapa consiste na confirmação dos pixeis da classe nuvem a partir das sombras já confirmadas. O relacionamento é feito através da medida de largura das nuvens e das sombras. A partir do ângulo de elevação solar e das alturas máxima e mínima da nuvem determina-se, partindo-se dos pixeis candidatos à nuvem, quais deles têm possibilidade de projetar sombras na área imageada. As primeiras sombras encontradas dentro das áreas de projeção são confirmadas de acordo com um critério de tamanho. As sombras confirmadas são usadas para confirmar as nuvens. Nesse caso, procura-se, no sentido inverso de incidência dos raios solares. Os resultados dos testes mostraram que a correlação nuvem/sombra pode ser usada para melhorar o resultado da discriminação realizada inicialmente com grande número de falsos candidatos. Porém, o fato desse método somente ser aplicado para certos tipos de nuvens limita sua aplicação.

Champion (2012) apresenta um método que pressupõe a existência de imagens multitemporais. As nuvens são extraídas a partir de um método de crescimento de regiões. Numa primeira etapa sementes de nuvem são extraídas através de uma análise pixel a pixel entre as imagens multitemporais. Um pixel é caracterizado como nuvem na existência de uma alta variabilidade da

Bol. Ciênc. Geod., sec. Artigos, Curitiba, v. 22, nํ2, p.336-388, abr - jun, 2016. 
reflectância em pelo menos $2 / 3$ das imagens. O objetivo é extrair pelo menos um ponto para cada nuvem. Na segunda etapa, um algoritmo de crescimento de regiões é usado para extrair as nuvens. São usados dois critérios para agregar um pixel a região, um radiométrico e um de homogeneidade. No critério radiométrico, um pixel é agregado se seu valor estiver dentro de um limiar predefinido. $\mathrm{O}$ critério de homogeneidade espera que os vizinhos desse pixel satisfaçam o mesmo critério. $\mathrm{O}$ método mostrou-se eficiente na detecção de Cumulus. Porém, demonstrou pouca eficiência na detecção de névoa. $\mathrm{O}$ autor propõe uma solução de crescimento de regiões para a detecção de sombras. A ideia é extrair nuvens e sombras separadamente e depois validá-las considerando o ângulo de elevação solar e a altura aproximada das nuvens. O método também é fortemente dependente de um registro preciso entre as imagens multitemporais.

Li et al (2004) propõem um algoritmo para a produção de mosaico livre de nuvem e sombra a partir de imagens IKONOS e SPOT. Primeiramente, adotando-se uma imagem como referência se faz um balanceamento dos níveis de cinza entre as imagens. Baseando-se apenas em limiares, produz-se uma máscara de nuvem e uma máscara de sombra. Nesse ponto, pixeis de solo exposto ou de construção podem ser confundidos com pixeis de nuvem. Visto que essas feições são produzidas pelo homem, um método para detecção de linhas e formas, análise de cor e tamanho é usado para eliminar falsos candidatos. Geralmente, as máscaras produzidas por limiares excluem as bordas das nuvens pelo fato das nuvens serem mais finas nessa região. Além disso, pode-se verificar também a presença de buracos. Esses problemas são resolvidos com a aplicação de um filtro morfológico para dilatar as nuvens detectadas. As sombras próximas às bordas das nuvens são extraídas a partir do conhecimento da geometria de visada do sensor e da geometria de iluminação solar. Com esses dados se pode inferir a localização aproximada das sombras. No processo de definição das máscaras, muitos pixeis, devido a semelhança na resposta espectral, são classificados erroneamente como nuvem e sombra. Assim, todos os pixeis da imagem passam por um ranqueamento para dizer o quanto um pixel pode ser nuvem e o quanto pode ser sombra. A partir do histograma da imagem, definem-se limiares para vegetação, nuvem e sombra. Os pixeis não nuvem e não sombra são classificados como vegetação, solo e outros. Baseado em um conjunto de regras e nos limiares definidos automaticamente, os pixeis da imagem são ranqueados. No final, os pixeis com ranque-1 e ranque-2 são usados para gerar os mosaicos livre de nuvens e sombras. Um novo balanceamento é feito no merge das imagens para reduzir as descontinuidades.

Song e Civco (2002) apresentam uma solução para reduzir nuvens e sombras em imagens multitemporais das bandas 1 e 4 do LANDSAT-5 TM. O autor considera que a variação do relevo influencia significativamente a resposta radiométrica das feições. Assim, em um primeiro passo, as imagens multitemporais passam por uma normalização radiométrica topográfica. Essa normalização faz com que feições de mesma característica tenham a mesma resposta, mesmo com variações de relevo. Uma outra correção é aplicada nas imagens para corrigir o efeito das diferentes condições atmosféricas e diferentes ângulos de iluminação existente entre as imagens. O método utiliza duas imagens da mesma região de diferentes datas e baseia-se no princípio de detecção de mudanças. Assim, a ideia é detectar nuvens e sombras existentes em apenas umas dessas imagens. A observação da resposta espectral dos alvos mostrou que a imagem da banda 1 possui melhores condições para detectar nuvens e a imagem da banda 4 para detectar sombra. São definidos limiares empiricamente para as imagens das datas 1 e 2 . Juntamente a isso, tem-se a imagem diferença. Os pixeis de nuvem e sombras detectados em regiões de diferença significativas são considerados como tal. Nuvens coincidentes não são detectadas nesse método.

Irish (2000) desenvolveu um algoritmo para detectar nuvens e sombras em imagens ETM+ a bordo do LANDSAT-7. O método é dividido em dois passos básicos. No primeiro, propriedades termais e reflexivas são usadas para classificar as nuvens. Isso é feito a partir de oito filtros baseados na assinatura espectral das nuvens. As bandas 2 a 5 são convertidas para reflectância no topo da atmosfera e a banda 6 para temperatura. No primeiro passo define-se uma assinatura confiável 
para as nuvens. Essa assinatura é usada para identificar as nuvens restantes no segundo passo. O segundo passo da solução proposta envolve uma análise termal e utiliza os dados de temperatura provenientes da banda 6 . Existe ainda um critério de homogeneidade que classifica um pixel como nuvem se ao menos cinco dos seus oito vizinhos são classificados como nuvem. $O$ algoritmo trabalha bem para grande parte da Terra. Problemas existem em regiões de neve em latitudes extremas e com ângulo de iluminação elevado.

Zhu e Woodcock (2011) também propõem um método para detectar nuvens e sombras em imagens LANDSAT. Da mesma forma como em Irish (2000) as propriedades físicas das imagens são levadas em conta para detectar potenciais áreas de nuvens e potenciais áreas de sombras. Assim, são usadas imagens de reflectância no topo da atmosfera e a imagem temperatura. As potenciais nuvens são correlacionadas com as potenciais sombras, gerando assim as máscaras de nuvem e sombra. Na presença de neve na cena, o algoritmo também produz uma máscara de neve. Primeiramente, potenciais pixeis de nuvem são separados dos demais a partir de diversos filtros. O primeiro filtro utiliza a reflectância da banda 7, a temperatura e os índices NDVI e NDSI (Normalized Difference Snow Index) para detectar potenciais pixeis de nuvem. O segundo filtro leva em conta a alta reflectância das nuvens nas bandas do visível. O terceiro filtro utiliza as reflectâncias das bandas 1 e 3 levando em consideração que a resposta espectral de nuvens finas e névoa são bem diferentes entre as bandas do azul e do vermelho. $\mathrm{O}$ quarto filtro utiliza as reflectâncias das bandas 4 e 5 para excluir rochas e deserto. Esses quatro filtros são usados para definir os potencias pixeis de nuvem. A partir do NDVI e da reflectância da banda 4 o quinto filtro separa os pixeis da imagem em duas classes, água e solo. Essas classes são usadas para determinar a probabilidade de nuvem sobre água e sobre solo. É possível refinar as potenciais áreas de nuvens a partir dessas probabilidades. O efeito escuro das sombras de nuvens no infravermelho próximo é usado para gerar os potenciais pixeis de sombra. Sombra de nuvem é iluminada por luz espalhada. Isso faz com que a resposta espectral seja relativamente baixa em comprimentos de ondas maiores. Os potenciais pixeis de sombra são detectados a partir banda 4 pela aplicação da transformação morfológica Flood-Fill. Os potenciais pixeis de neve são definidos a partir das reflectâncias das bandas 2 e 4, temperatura e do NDSI. A partir do ângulo de visada do sensor, ângulos zenital e azimute solar e da altura relativa das nuvens é possível inferir a posição das sombras baseando-se no relacionamento geométrico entre uma nuvem e sua sombra. As nuvens e sombras são correlacionadas partindo-se do princípio que suas formas são similares. Além disso, visto que as nuvens podem ser extensas verticalmente, o algoritmo trata cada nuvem como um objeto 3D. O método determina as alturas máxima e mínima das nuvens a partir da temperatura. O método mostrou ser muito eficiente na detecção de nuvens, sombras e neve. A acurácia média do método ficou em torno de $96,4 \%$ para um conjunto de cenas distribuídas globalmente.

\section{A Câmera AWFI a Bordo do Satélite AMAZONIA-1}

A câmera AWFI planejada para estar a bordo do satélite AMAZONIA-1 será uma atualização da WFI desenvolvida para os satélites CBERS-3/4. As principais características dessa câmera são apresentadas na tabela 1 abaixo.

Tabela 1: Características principais da câmera AWFI

Bol. Ciênc. Geod., sec. Artigos, Curitiba, v. 22, nํ2, p.336-388, abr - jun, 2016. 


\begin{tabular}{l|l|l|l}
\hline Distância Focal & \multicolumn{1}{|c|}{ Bandas Espectrais } & $\begin{array}{c}\text { Resolução } \\
\text { Espacial }\end{array}$ & $\begin{array}{c}\text { Largura da Faixa } \\
\text { Imageada }\end{array}$ \\
\hline $251 \mathrm{~mm}$ & Banda $1: 450-520 \mathrm{~nm}$ & $40 \mathrm{~m}$ & $720 \mathrm{~km}$ \\
& Banda $2: 520-590 \mathrm{~nm}$ & & \\
& Banda $3: 630-690 \mathrm{~nm}$ & & \\
& Banda $4: 770-890 \mathrm{~nm}$ & & \\
\hline
\end{tabular}

\section{Detecção de Nuvem e Sombra de Nuvem}

A detecção de nuvem baseia-se na solução proposta por Zhu e Woodcock (2011). A figura 1 dá uma visão geral do processamento. Como pode ser visto, a máscara de nuvem é obtida a partir das máscaras de NDVI, Whiteness Index (WI) e Haze Optimized Transformation (HOT). A detecção de sombra de nuvem é feita a partir da integração das máscaras de pixeis escuros e água com a imagem resultante da diferença entre a cena a ser classificada e uma referência da mesma região (figura 2). Todos os cálculos são realizados a partir das reflectâncias no topo da atmosfera (ToA) das bandas do azul (B1), verde (B2), vermelho (B3) e infravermelho próximo (B4). Os processamentos são descritos com mais detalhes nas seções que seguem.

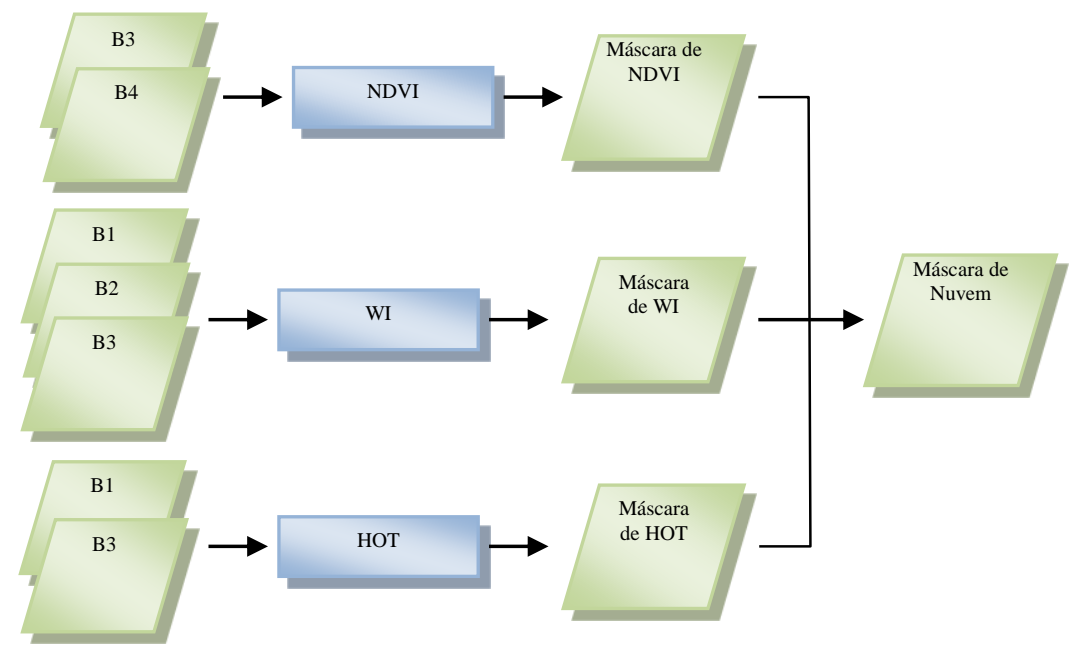

Figura 1: Detecção de nuvem. 


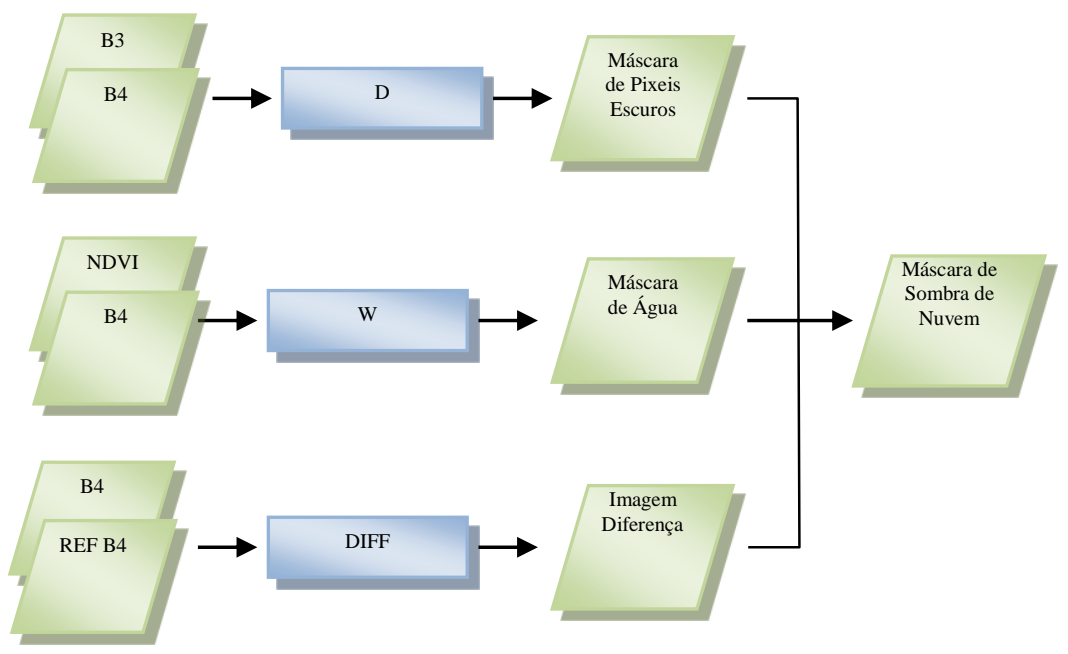

Figura 2: Detecção de sombra de nuvem.

\subsection{Geração de Imagem de Reflectância no Topo da Atmosfera}

A equação 1, descrita em Chander et al. (2009), mostra como calcular a reflectância ToA.

$$
\rho_{\lambda}=\frac{\pi \cdot L_{\lambda} \cdot d^{2}}{\operatorname{ESUN}_{\lambda} \cdot \cos (\theta)}
$$

Na equação 1, $\rho_{\lambda}$ é a reflectância ToA (adimensional). $\mathrm{L}_{\lambda}$ é a radiância bidirecional aparente $\left(\mathrm{W} /\left(\mathrm{m}^{2}\right.\right.$.sr. $\left.\left.\mu \mathrm{m}\right)\right)$. A distância Sol-Terra em unidades astronômicas é representada por d. ESUN $\mathrm{N}_{\lambda}$ é a irradiância solar exoatmosférica média no topo da atmosfera $\left(\mathrm{W} /\left(\mathrm{m}^{2} . \mu \mathrm{m}\right)\right)$. Finalmente, $\theta$ é o ângulo zenital solar (rad).

A radiância $\left(\mathrm{L}_{\lambda}\right)$ é determinada a partir da calibração absoluta do sensor e relaciona linearmente números digitais com medidas de radiância. Os valores calibrados de radiância mínima e máxima que um sensor é capaz de registrar são fornecidos pelos responsáveis do satélite. A partir desses parâmetros, a conversão de ND em radiância é resolvida a partir de uma interpolação linear, conforme mostra a equação 2 .

$$
L_{\lambda}=\left(\frac{L M A X_{\lambda}-L M I N_{\lambda}}{N D_{\max }-N D_{\min }}\right) \cdot\left(N D-N D_{\min }\right)+L M I N_{\lambda}
$$

A radiância espectral máxima que o sensor é capaz de registrar é representada por $\mathrm{LMAX}_{\lambda}$ $\left(\mathrm{W} /\left(\mathrm{m}^{2} . \mathrm{sr} . \mu \mathrm{m}\right)\right)$. $\mathrm{LMIN}_{\lambda}$ é a radiância espectral mínima $\left(\mathrm{W} /\left(\mathrm{m}^{2} . \mathrm{sr} . \mu \mathrm{m}\right)\right)$. $\mathrm{ND}_{\max }$ e $\mathrm{ND}_{\min }$ são os números digitais correspondentes a $\operatorname{LMAX}_{\lambda}$ e a $\operatorname{LMIN}_{\lambda}$, respectivamente. 


\subsection{Detecção de Nuvem}

Zhu e Woodcock (2011) utilizaram as bandas do LANDSAT para detectar nuvem e sombra de nuvem. Haja vista que as imagens AMAZONIA-1 AWFI vão atuar na faixa do visível e do infravermelho próximo nem todos os filtros apresentados pelos autores puderam ser utilizados. O método de detecção baseia-se então na aplicação de três filtros.

O primeiro filtro utiliza as bandas do vermelho (B3) e do infravermelho próximo (B4) para determinar o NDVI (equação 3). O NDVI é um índice discriminante de vegetação, que quanto mais próximo de 1 maior é a certeza de estar se tratando de um pixel de vegetação. Na detecção de nuvem espera-se NDVI próximo a zero para pixeis de nuvem devido sua aparência branca nas bandas envolvidas. Porém, como variações são esperadas, principalmente quando se trata de nuvens pouco espessas, define-se um intervalo de NDVI para separar os pixeis de nuvem dos demais (equação 4). Os pixeis aprovados nesse filtro definem a máscara de NDVI.

$$
\begin{aligned}
& N D V I=\frac{B 4-B 3}{B 4+B 3} \\
& N D V I_{\min }<N D V I<N D V I_{\max }
\end{aligned}
$$

A figura 3 apresenta um exemplo da imagem de NDVI usada na detecção de nuvem. Note na imagem de NDVI que os pixeis de nuvem são mais escuros que os demais.

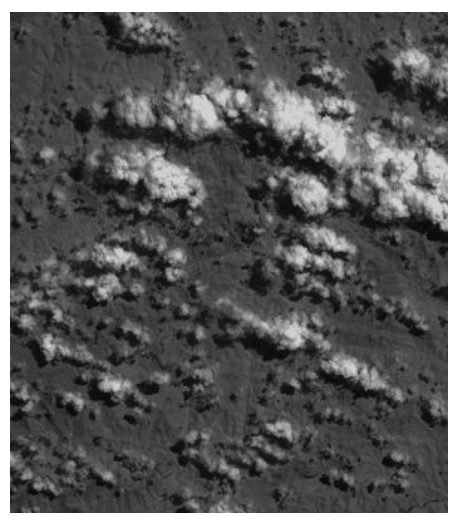

(a)

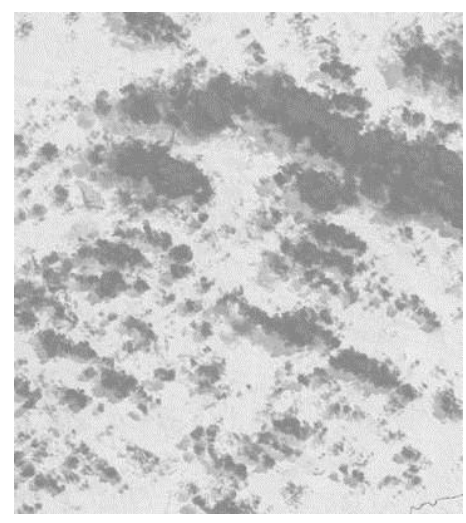

(b)

Figura 3: NDVI na detecção de nuvem. (a) Imagem de reflectância no topo da atmosfera da banda 4 do LANDSAT-5 TM; e (b) Imagem de NDVI.

O segundo filtro baseia-se no WI modificado por Zho e Woodcock (2011). O WI é definido sobre as bandas do azul (B1), do verde (B2) e do vermelho (B3), como um limiar sendo utilizado para excluir pixeis que não são brancos o suficiente para serem considerados nuvens (equação 6). Como se sabe, quanto menor o comprimento de onda de um fluxo radiante maior é a interferência da atmosfera. Para reduzir essa interferência no WI, como é mostrado na equação 5, nesse trabalho foram atribuídos pesos para cada uma das bandas $\left(\omega_{i}\right)$. A ideia é atribuir peso menor para as bandas sujeitas a maiores interferências atmosféricas. Os pixeis aprovados nesse filtro definem a máscara WI. 


$$
\begin{aligned}
M & =0.25 \cdot B 1+0.375 \cdot B 2+0.375 \cdot B 3 \\
W & =\sum_{i=1}^{3}\left|\frac{B i-M}{M}\right|<W_{\max }
\end{aligned}
$$

A figura 4 apresenta um exemplo da imagem de WI. Devido às nuvens apresentarem uma alta resposta para as bandas do visível, quanto mais próximo de zero o WI, maior o indício de se tratar de um pixel de nuvem.

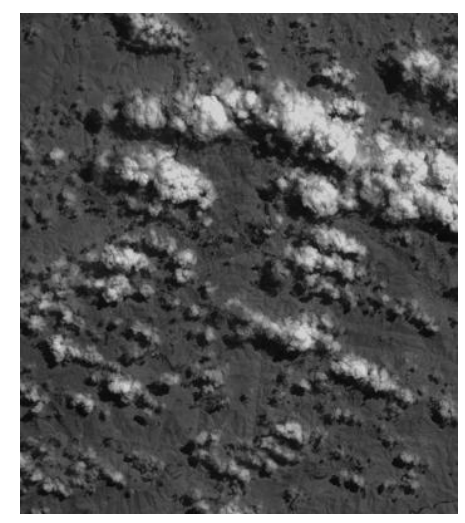

(a)

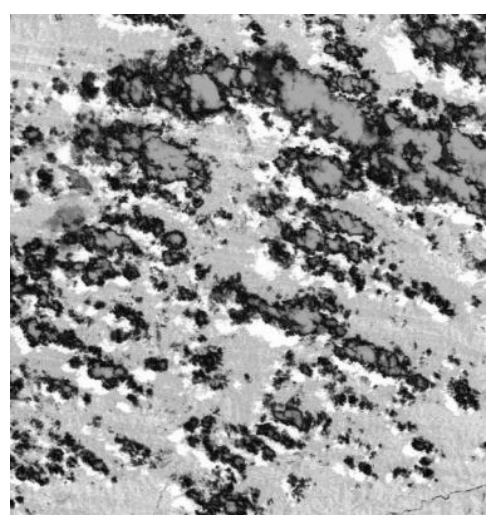

(b)

Figura 4: WI na detecção de nuvem. (a) Imagem de reflectância no topo da atmosfera da banda 4 do LANDSAT-5 TM; e (b) Imagem de WI.

O terceiro filtro toma como base a transformação proposta por Zhang et al. (2002). A ideia é que as bandas do visível sob céu limpo são altamente correlacionadas. Porém, a resposta espectral sob névoa é diferente entre os comprimentos de onda do azul e do vermelho. A HOT é dada pela equação 7.

$$
H O T=B 1-0.45 \cdot B 3-0.08>H O T_{\min }
$$

A figura 5 apresenta um exemplo da imagem HOT. Note que é possível separar pixeis de nuvens dos demais através dessa imagem.

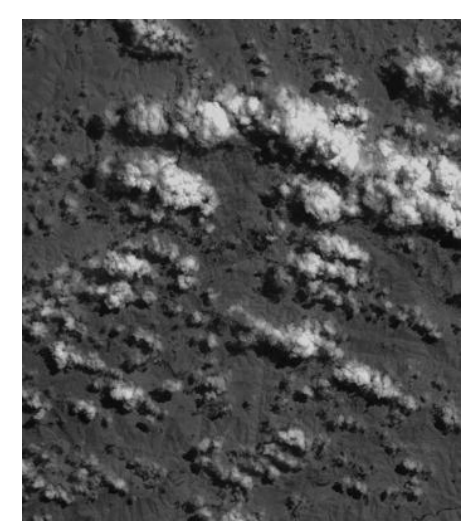

(a)

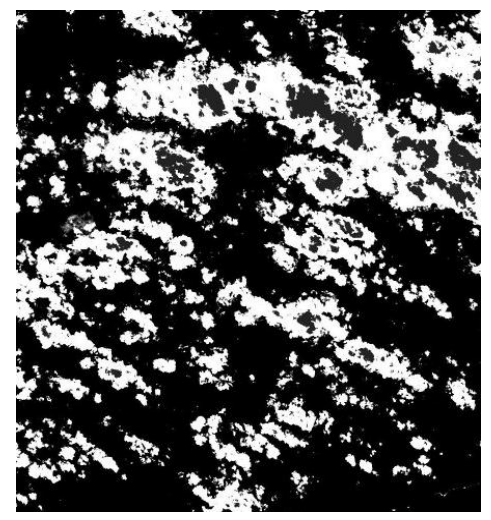

(b)

Figura 5: Imagem HOT na detecção de nuvem. (a) Imagem de reflectância no topo da atmosfera da banda 4 do LANDSAT-5 TM; e (b) Imagem HOT.

Os pixeis aprovados nas três filtragens definem a máscara de nuvem.

Bol. Ciênc. Geod., sec. Artigos, Curitiba, v. 22, nํ2, p.336-388, abr - jun, 2016. 


\subsection{Detecção de Sombra de Nuvem}

Conforme já foi mencionado anteriormente, a detecção de sombra de nuvem é feita a partir da integração das máscaras de pixeis escuros e água com a imagem diferença.

A máscara de pixeis escuros (D) segue a estratégia apresentada por Silva et al. (2007). Visando obter o maior número possível de candidatos, inclusive falsos positivos, utiliza-se um método paramétrico relaxado. Como mostra a equação 8, os pixeis escuros são extraídas a partir das reflectâncias das bandas 2 e 4.

$$
\begin{aligned}
& D_{2}=B 2<\left(B 2_{\min }+\rho_{\lambda 2}\right) \\
& D_{4}=B 4<\left(B 4_{\min }+\rho_{\lambda 4}\right) \\
& D=B 2 \text { and } B 4
\end{aligned}
$$

$\mathrm{Na}$ equação $8, \mathrm{~B} 2_{\min }$ e $\mathrm{B} 4_{\min }$ correspondem às menores reflectâncias encontradas para as bandas 2 e 4 , respectivamente. $\rho \lambda_{2}$ e $\rho \lambda_{4}$ são limiares de reflectância para as duas bandas em análise.

Os pixeis aprovados nos dois testes definem a máscara de pixeis escuros.

A máscara de pixeis escuros é apresentada pela figura 6. Note que grande parte dos pixeis escuros faz parte dessa máscara (em verde).

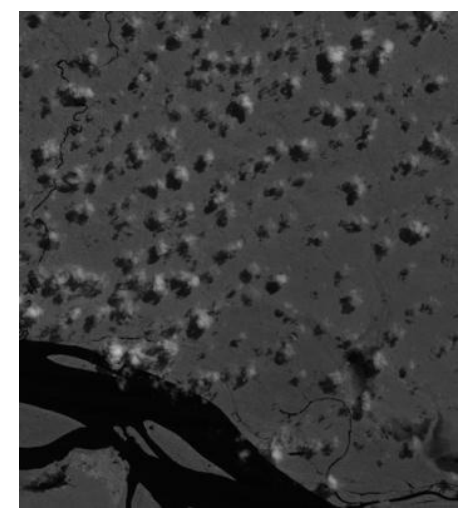

(a)

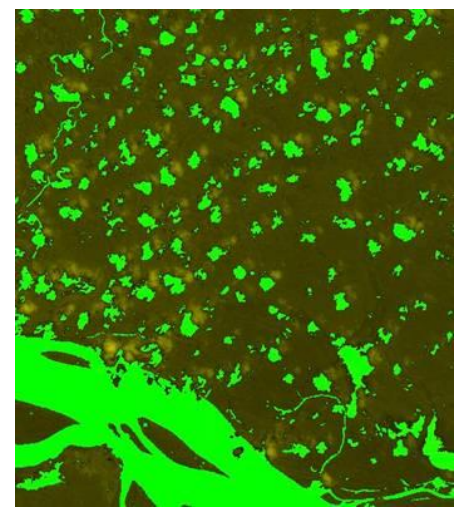

(b)

Figura 6: Máscara de pixeis escuros. (a) Imagem de reflectância no topo da atmosfera da banda 4 do LANDSAT-5 TM; e (b) Máscara de pixeis escuros considerando $\rho \lambda 2=0.1$ e $\rho \lambda 4=0.16$.

A máscara de água (W) é obtida a partir das reflectâncias da banda 4 e do NDVI (Zhu e Woodcock, 2011). Visto que a água geralmente é escura na faixa do infravermelho próximo, a reflectância da banda 4 é um excelente indicador de água. Além disso, o NDVI pode ser usado para separar pixeis de água e de solo. A equação 9 é usada para detectar água turva ou água limpa.

$$
W=\left(N D V I<N D V I_{\text {clean }} \text { and } B 4<\rho_{\lambda \text { clean }}\right) \text { or }\left(N D V I<N D V I_{\text {turbid }} \text { and } B 4<\rho_{\lambda \text { turbid }}\right)
$$




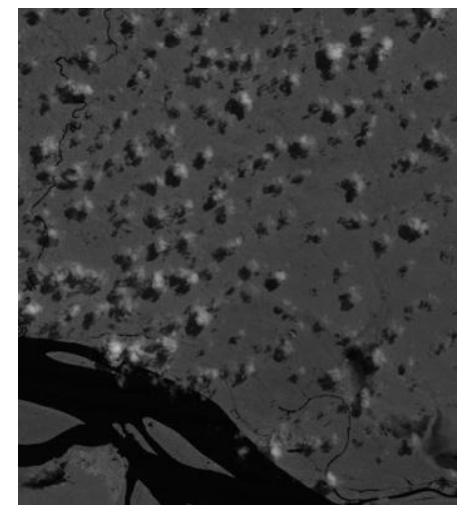

(a)

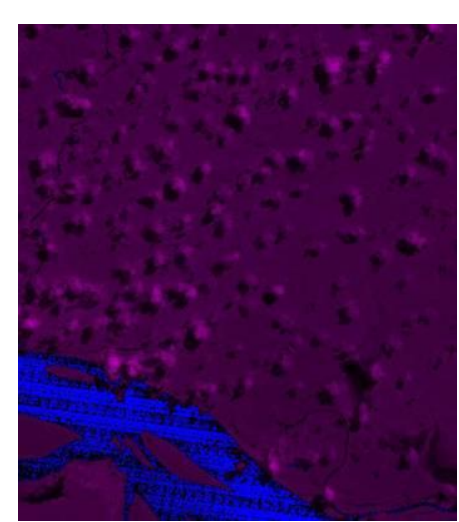

(b)

Figura 7: Máscara de água. (a) Imagem de reflectância no topo da atmosfera da banda 4 do LANDSAT-5 TM; e (b) Máscara de água (pixeis de água em azul) considerando $\mathrm{NDVI}_{\text {clean }}=-0.1$,

$$
\rho \lambda_{\text {clean }}=0.11, \text { NDVI }_{\text {turbid }}=-0.1 \text { e } \rho \lambda_{\text {turbid }}=0.05 \text {. }
$$

A imagem diferença (DIFF) é obtida a partir da diferença entre a imagem que desejamos classificar e uma referência da mesma região, idealmente sem nuvens (equação 10). Para a determinação das diferenças, a banda 4 e sua referência devem estar perfeitamente registradas. Isso é garantido a partir de um processamento paralelo baseado em GPU (Graphics Processing Unit) que determina o coeficiente de correlação entre as imagens pixel a pixel. Esse processamento resulta em duas imagens de deslocamento em linhas e colunas. Esses deslocamentos são usados em um processamento posterior, o que permite um registro perfeito entre as imagens (Liporace, 2013).

$$
D I F F=B 4-R E F B 4
$$

A imagem diferença permite reduzir a quantidade de dados a serem analisados, visto que são considerados apenas os pixeis com diferenças significativas. Grandes diferenças são um indicativo de mudanças na imagem, que podem ser causadas por mudanças no terreno ou interferências como nuvens e suas sombras. O sinal da diferença também é uma fonte de informação. Sinal negativo indica um escurecimento do pixel. Esse escurecimento pode ter sido causado pela presença de uma sombra de nuvem. Assim, apenas as diferenças negativas são analisadas. Para minimizar o efeito de diferenças sazonais e das condições atmosféricas no momento da aquisição das imagens é feito um balanceamento radiométrico entre as imagens.

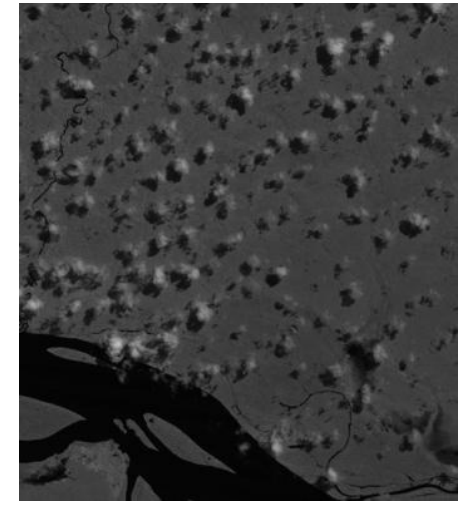

(a)

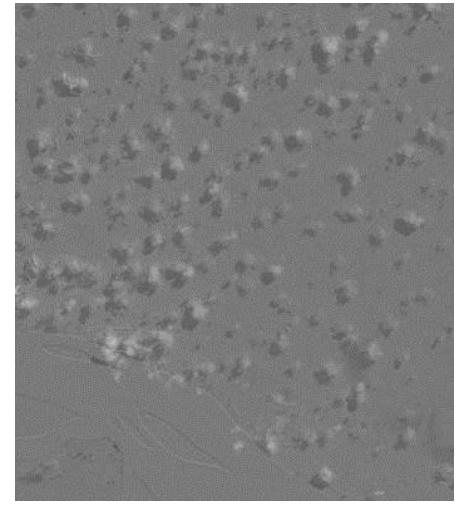

(b)

Figura 8: Imagem diferença na detecção de sombra de nuvem. (a) Imagem de reflectância ToA da banda 4 do LANDSAT-5 TM; e (b) Imagem diferença. 
A figura 8 apresenta a imagem diferença. Os pixeis escuros nessa imagem são representados por diferença negativa.

Quando a imagem diferença é integrada com as máscaras de pixeis escuros e água é possível separar sombra de nuvem das demais feições. Como mostra a equação 11 , um pixel é considerado como sombra de nuvem se ele é escuro, não é água e a diferença negativa for menor do que um limiar.

$$
C S=D \text { and NOT }(W) \text { and }\left(D I F F<D I F F_{\min }\right)
$$

\subsection{Pós-Processamento}

As máscaras de nuvem e sombra de nuvem são ainda pós-processadas a fim de serem corrigidos pequenos problemas oriundos da classificação. São utilizados três métodos: buffer, análise de vizinhança e confirmação das sombras de nuvem.

O buffer dilata a área classificada considerando um número pré-definido de pixeis. Esse processo corrige bordas e pequenos buracos não classificados.

A análise de vizinhança verifica se um número pré-definido de vizinhos de um pixel recebeu a mesma classificação. Caso contrário, o pixel é tratado como ruído e a classificação é desconsiderada.

A confirmação das sombras de nuvem considera o fato de sempre existir um pixel de nuvem para um pixel de sombra. Assim, o método verifica a existência de um pixel de nuvem dentro de uma região em torno de um pixel de sombra. Caso nenhum seja encontrado, a classificação como sombra de nuvem é desconsiderada.

\section{Discussões dos Resultados}

Devido à inexistência de imagens AMAZONIA-1 AWFI os experimentos foram conduzidos a partir de cenas LANDSAT-5 TM. Como o objetivo do trabalho é a detecção de nuvem e sombra de nuvem em imagens de sensores que atuam na faixa do visível e do infravermelho próximo foram utilizadas apenas as bandas de 1 a 4 desse sensor. As características das imagens utilizadas nos testes são apresentadas na Tabela 2. As imagens de referência usadas no processo de detecção de sombra de nuvem consistem de tiles de um mosaico do Brasil gerado a partir de imagens GLS2010 (Global Land Survey, 2010).

Tabela 2: Características das imagens usadas nos testes.

\begin{tabular}{l|l|l|l|l}
\hline Satélite & Sensor & Data da Passagem & Órbita & Ponto \\
\hline LANDSAT-5 & TM & $2007 / 07 / 24$ & 001 & 060 \\
\hline LANDSAT-5 & TM & $2007 / 07 / 06$ & 003 & 056 \\
\hline LANDSAT-5 & TM & $2007 / 07 / 08$ & 218 & 065 \\
\hline
\end{tabular}

Bol. Ciênc. Geod., sec. Artigos, Curitiba, v. 22, no2, p.369-388, abr - jun, 2016. 
Para avaliar o desempenho dos classificadores foram geradas máscaras de nuvem e de sombra de nuvem de referência para cada uma das cenas usadas nos testes. As máscaras foram geradas manualmente por um analista de imagens. A análise é feita comparando-se pixel a pixel as máscaras de referência com as extraídas automaticamente. Essa comparação resulta nos seguintes percentuais:

$\%$ de pixeis classificados como nuvem ou sombra de nuvem com acerto;

$\%$ de pixeis não classificados como nuvem ou sombra de nuvem com acerto;

$\%$ de pixeis classificados como nuvem ou sombra de nuvem com erro (falso positivo); e

$\%$ de pixeis não classificados como nuvem ou sombra de nuvem com erro (falso negativo).

As coberturas percentuais de nuvem (CC) e de sombra de nuvem (CSC) são dadas pela soma dos percentuais de pixeis classificados com acerto e dos falsos negativos (equações 12 e 13).

$$
\begin{gathered}
C C=\left(\begin{array}{l}
\% \text { de pixels classificados comonuvem com acerto }+ \\
\% \text { de pixels não classificados comonuvem com erro }
\end{array}\right) \\
C S C=\left(\begin{array}{l}
\% \text { de pixels classificados como sombra de nuvem com acerto }+ \\
\% \text { de pixels não classificados como sombra de nuvem com erro }
\end{array}\right)
\end{gathered}
$$

A acurácia global dos classificadores, GCA e GCSA, considera o percentual de acerto dos classificadores levando em conta os percentuais de pixeis classificados com acerto e não classificados com acerto.

$$
\begin{gathered}
G C A=\left(\begin{array}{l}
\% \text { de pixels classificados comonuvem com acerto }+ \\
\% \text { de pixels não classificados comonuvem com acerto }
\end{array}\right) \\
G C S A=\left(\begin{array}{l}
\% \text { de pixels classificados como sombra de nuvem com acerto }+ \\
\% \text { de pixels na a classificados como sombra de nuvem com acerto }
\end{array}\right)
\end{gathered}
$$

A acurácia de cada classificador, CA e CSA, é dada pela cobertura de nuvem ou sombra de nuvem e pelos percentuais de pixeis classificados como nuvem ou sombra de nuvem com acerto (equações 16 e 17).

$$
\begin{gathered}
C A=\frac{\% \text { de pixels classificados comonuvem com acerto }}{C C} \\
C S A=\frac{\% \text { de pixels classificados comosombrade nuvem com acerto }}{C S C}
\end{gathered}
$$

A figura 9 apresenta a cena LANDSAT-5 TM 2007/07/24 001/060. As figuras 7(a) e 7(b) apresentam uma composição colorida do tipo 342. Note que essa cena é encoberta por nuvens espessas. Verifique também a presença de corpos d'água. Corpos d'água podem ser confundidos com sombra de nuvem. 


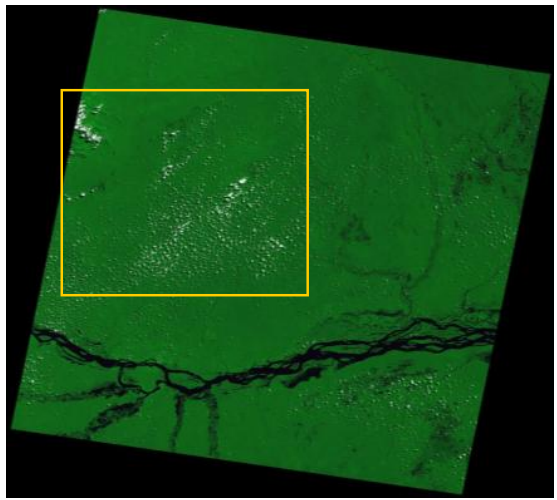

(a)

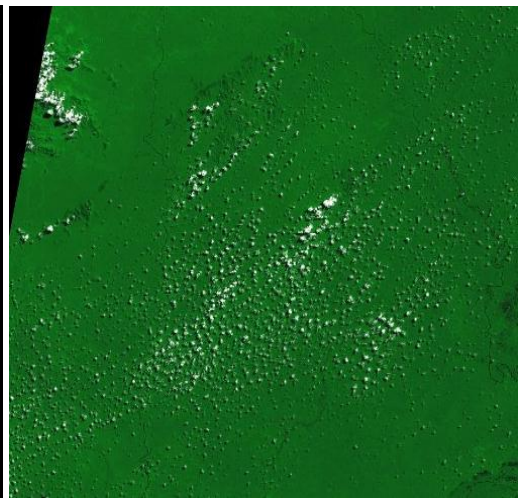

(b)

Figura 9: Cena 001/060. (a) Composição colorida 342; (b) Realce das nuvens e sombras de nuvens presentes na imagem.

Na figura 10 são apresentados os resultados da classificação de nuvem. A figura 10(a) apresenta a máscara de nuvem gerada pelo classificador e a figura 10(b) apresenta a máscara de referência gerada manualmente por um analista de imagens. Os percentuais calculados a partir da comparação dessas duas imagens são apresentados na tabela 3. De acordo com a equação 12, 5.20\% dos pixeis da cena são nuvem, sendo que $3.61 \%$ foram classificados com acerto e os $1.59 \%$ dos pixeis restantes erroneamente deixaram de ser classificados. Isso resulta numa acurácia do classificador de $69,42 \%$. A acurácia global da classificação, que considera os pixeis classificados e não classificados com acerto, resultou em $98,04 \%$.

Tabela 3: Resultados da classificação de nuvem da cena 001/060.

\begin{tabular}{l|l|l|l}
\hline $\begin{array}{c}\text { \% de pixeis classificados } \\
\text { como nuvem com acerto }\end{array}$ & $\begin{array}{c}\text { \% de pixeis não classificados } \\
\text { como nuvem com acerto }\end{array}$ & $\begin{array}{c}\text { \% de falsos } \\
\text { positivos }\end{array}$ & $\begin{array}{c}\text { \% de falsos } \\
\text { negativos }\end{array}$ \\
\hline $3.61 \%$ & $94.43 \%$ & $0.37 \%$ & $1.59 \%$ \\
\hline
\end{tabular}

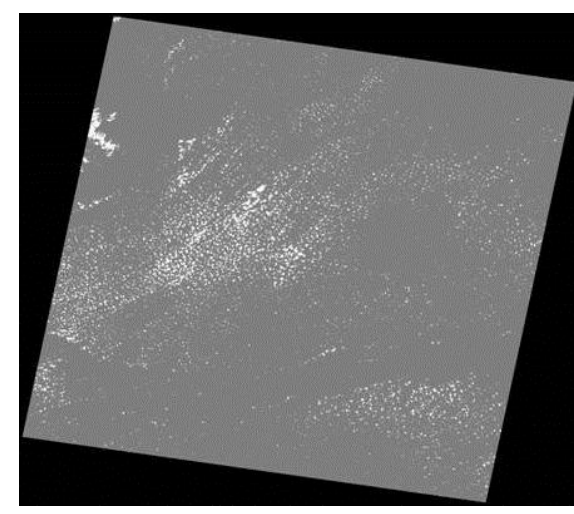

(a)

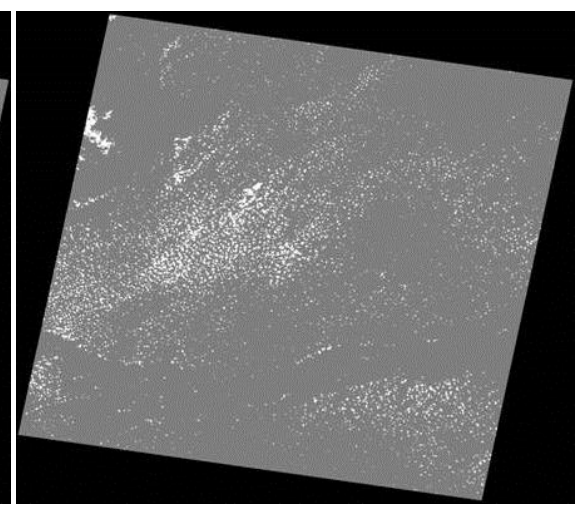

(b)

Figura 10: Máscaras de nuvem da cena 001/060. (a) Máscara gerada pelo classificador de nuvem; (b) Máscara de nuvem de referência.

A figura 11 apresenta os resultados da classificação de sombra de nuvem. Os percentuais calculados a partir da comparação das máscaras automática e de referência são apresentados na tabela 4. Pela equação 13 tem-se que $3.03 \%$ dos pixeis da cena são sombra de nuvem, sendo que 
$2.57 \%$ foram classificados com acerto e os $0.46 \%$ restantes erroneamente deixaram de ser classificados. A acurácia do classificador nesse caso foi de $84,82 \%$. A acurácia global da classificação foi de $97,50 \%$.

Tabela 4: Resultados da classificação de sombra de nuvem da cena 001/060.

\begin{tabular}{l|l|c|c}
\hline $\begin{array}{l}\text { \% de pixeis classificados como } \\
\text { sombra de nuvem com acerto }\end{array}$ & $\begin{array}{c}\text { \% de pixeis não classificados } \\
\text { como sombra de nuvem com } \\
\text { acerto }\end{array}$ & $\begin{array}{c}\text { \% de } \\
\text { falsos } \\
\text { positivos }\end{array}$ & $\begin{array}{c}\text { \% de } \\
\text { falsos } \\
\text { negativos }\end{array}$ \\
\hline $2.57 \%$ & $94.93 \%$ & $2.04 \%$ & $0.46 \%$ \\
\hline
\end{tabular}

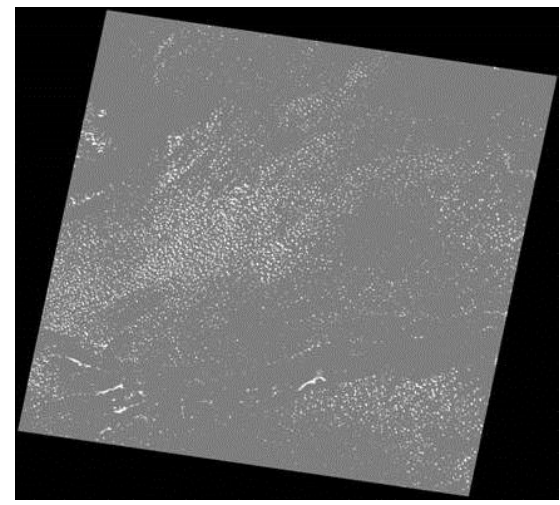

(a)

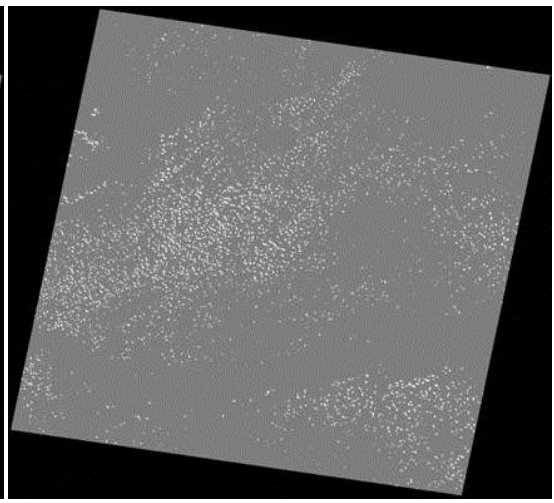

(b)

Figura 11: Máscaras de sombra de nuvem da cena 001/060. (a) Máscara gerada pelo classificador de sombra de nuvem; (b) Máscara de sombra de nuvem de referência.

A figura 12 apresenta a cena LANDSAT-5 TM 2007/07/06 003/056. As figuras 10(a) e 10(b) apresentam uma composição colorida do tipo 342. Note que essa cena é encoberta tanto por nuvens espessas quanto por névoa. Verifique também a presença de corpos d'água.

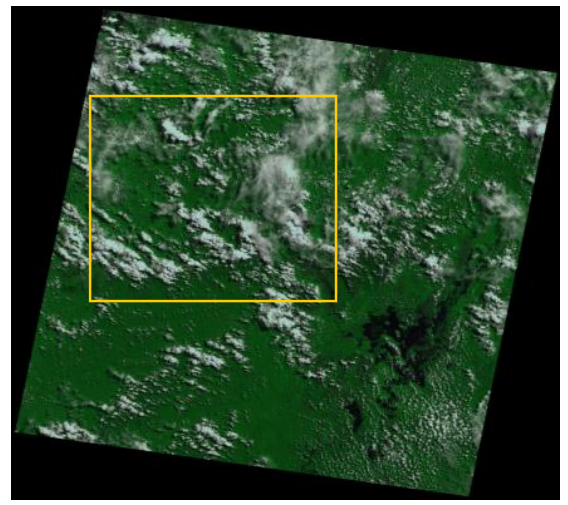

(a)

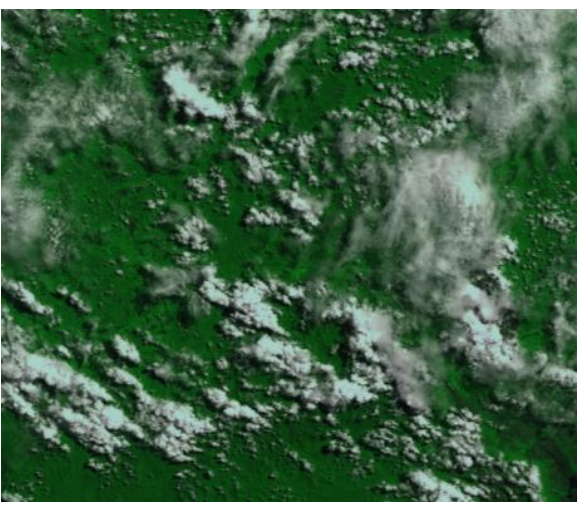

(b)

Figura 12: Cena 003/056. (a) Composição colorida 342; (b) Realce das nuvens e sombras de nuvens presentes na imagem.

Os resultados da classificação de nuvem da cena 003/056 são apresentados pela figura 13. A figura 13(a) apresenta a máscara de nuvem gerada pelo classificador. A figura 13(b) apresenta a máscara de referência. Os percentuais calculados a partir da comparação dessas duas imagens são Bol. Ciênc. Geod., sec. Artigos, Curitiba, v. 22, nํ2, p.336-388, abr - jun, 2016. 
apresentados na tabela 5. $45.31 \%$ dos pixeis dessa cena são nuvem, sendo $44.61 \%$ classificados com acerto. Os $0.70 \%$ dos pixeis restantes erroneamente não foram classificados. A acurácia do classificador foi de $98,46 \%$. Porém, a acurácia global da classificação foi de 90,61\%. Isso se deve ao percentual de $8.69 \%$ de falsos positivos.

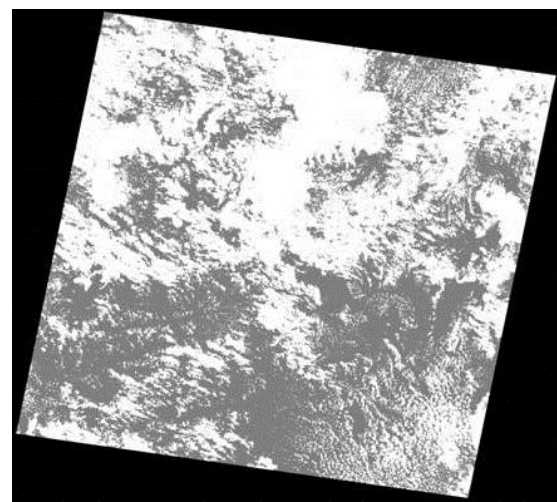

(a)

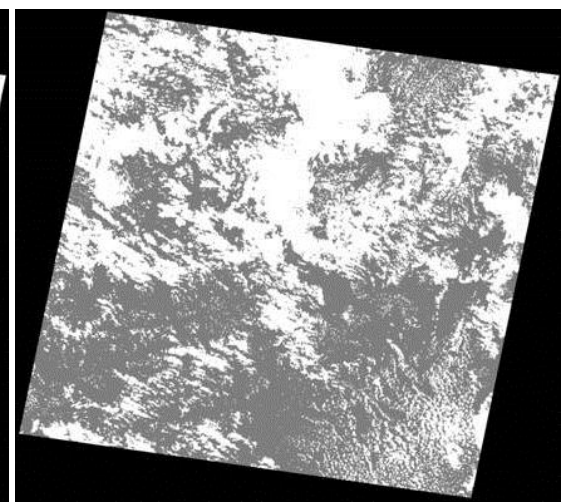

(b)

Figura 13: Máscaras de nuvem da cena 003/056. (a) Máscara gerada pelo classificador de nuvem; (b) Máscara de nuvem de referência.

Tabela 5: Resultados da classificação de nuvem da cena 003/056.

\begin{tabular}{l|l|l|l}
\hline $\begin{array}{c}\text { \% de pixeis classificados } \\
\text { como nuvem com acerto }\end{array}$ & $\begin{array}{c}\text { \% de pixeis não classificados } \\
\text { como nuvem com acerto }\end{array}$ & $\begin{array}{c}\text { \% de falsos } \\
\text { positivos }\end{array}$ & $\begin{array}{c}\text { \% de falsos } \\
\text { negativos }\end{array}$ \\
\hline $44.61 \%$ & $46.00 \%$ & $8.69 \%$ & $0.70 \%$ \\
\hline
\end{tabular}

A figura 14 apresenta os resultados da classificação de sombra de nuvem. A tabela 6 apresenta os percentuais calculados a partir da comparação das máscaras automática e de referência. Pela equação 13 tem-se que $14.59 \%$ dos pixeis da cena são sombra de nuvem. $7.87 \%$ foram classificados com acerto e $6.72 \%$ erroneamente deixaram de ser classificados. A acurácia do classificador nesse caso foi de 53.94\%. Os $6.72 \%$ dos pixeis da cena de sombra de nuvem não classificados contribuíram para essa acurácia. Mesmo assim, a acurácia global da classificação foi de $89,87 \%$.

Tabela 6: Resultados da classificação de sombra de nuvem da cena 003/056.

\begin{tabular}{l|l|c|c}
\hline $\begin{array}{c}\text { \% de pixeis classificados como } \\
\text { sombra de nuvem com acerto }\end{array}$ & $\begin{array}{c}\text { \% de pixeis não classificados } \\
\text { como sombra de nuvem com } \\
\text { acerto }\end{array}$ & $\begin{array}{c}\text { \% de } \\
\text { falsos } \\
\text { positivos }\end{array}$ & $\begin{array}{c}\text { \% de } \\
\text { falsos } \\
\text { negativos }\end{array}$ \\
\hline $7.87 \%$ & $82.00 \%$ & $3.41 \%$ & $6.72 \%$ \\
\hline
\end{tabular}




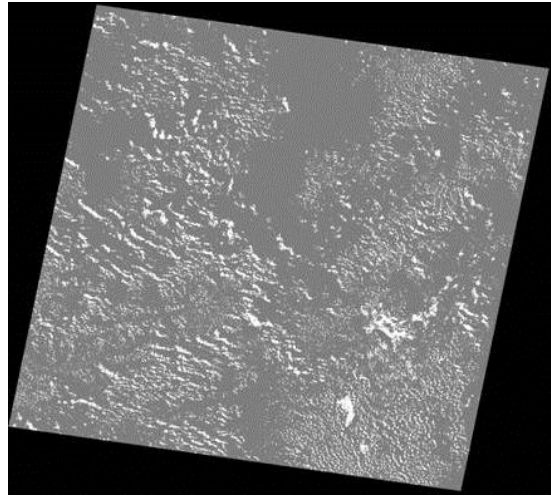

(a)

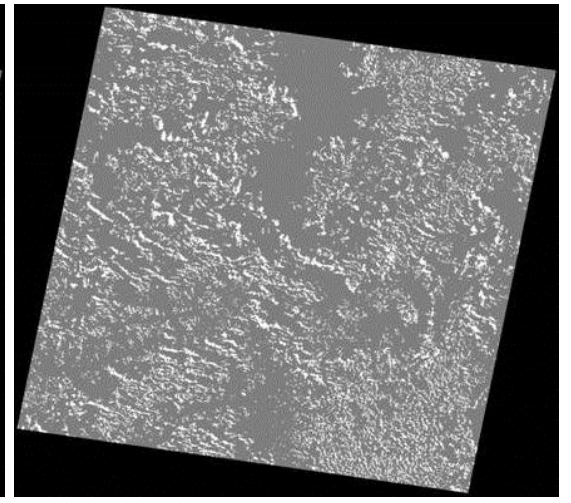

(b)

Figura 14: Máscaras de sombra de nuvem da cena 003/056. (a) Máscara gerada pelo classificador de sombra de nuvem; (b) Máscara de sombra de nuvem de referência.

A cena LANDSAT-5 TM 2007/07/08 218/065 é apresentada pela figura 15 através de uma composição colorida do tipo 342. Note que essa cena é encoberta tanto por nuvens espessas quanto por névoa.

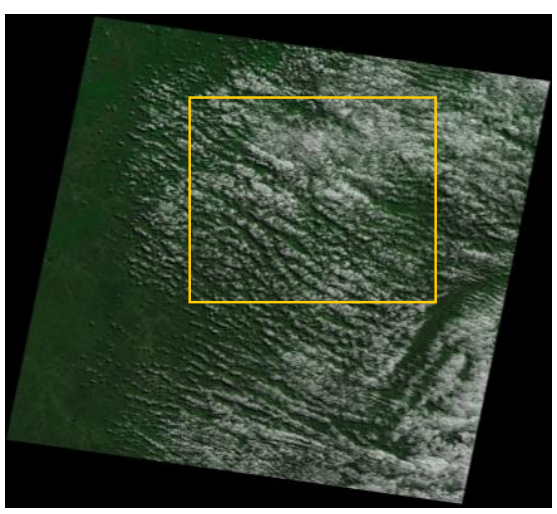

(a)

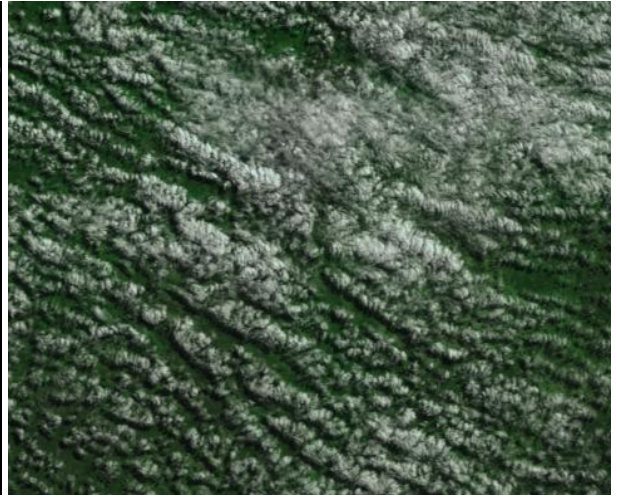

(b)

Figura 15: Cena 218/065. (a) Composição colorida 342; (b) Realce das nuvens e sombras de nuvens presentes na imagem.

Os resultados da classificação de nuvem dessa cena são apresentados pela figura 16. A figura 16(a) apresenta a máscara de nuvem gerada pelo classificador e a figura 16(b) apresenta a máscara de referência. Os percentuais calculados a partir da comparação dessas duas imagens são apresentados na tabela 7. Pela equação 12 , tem-se que $47.38 \%$ dos pixeis dessa cena são nuvem, sendo $44.61 \%$ classificados com acerto. Os $2.77 \%$ dos pixeis restantes erroneamente não foram classificados. A acurácia do classificador foi de $98.23 \%$. A acurácia global da classificação foi de $89.54 \%$ devido também ao percentual elevado de $9.62 \%$ de falsos positivos.

Tabela 7: Resultados da classificação de nuvem da cena 218/065.

\begin{tabular}{l|l|l|l}
\hline $\begin{array}{c}\text { \% de pixeis classificados } \\
\text { como nuvem com acerto }\end{array}$ & $\begin{array}{c}\text { \% de pixeis não classificados } \\
\text { como nuvem com acerto }\end{array}$ & $\begin{array}{c}\text { \% de falsos } \\
\text { positivos }\end{array}$ & $\begin{array}{c}\text { \% de falsos } \\
\text { negativos }\end{array}$ \\
\hline $46.54 \%$ & $43.00 \%$ & $9.62 \%$ & $0.84 \%$ \\
\hline
\end{tabular}

Bol. Ciênc. Geod., sec. Artigos, Curitiba, v. 22, nํ2, p.336-388, abr - jun, 2016. 


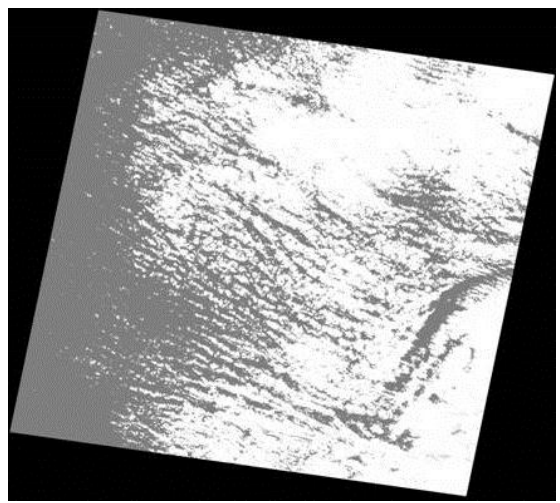

(a)

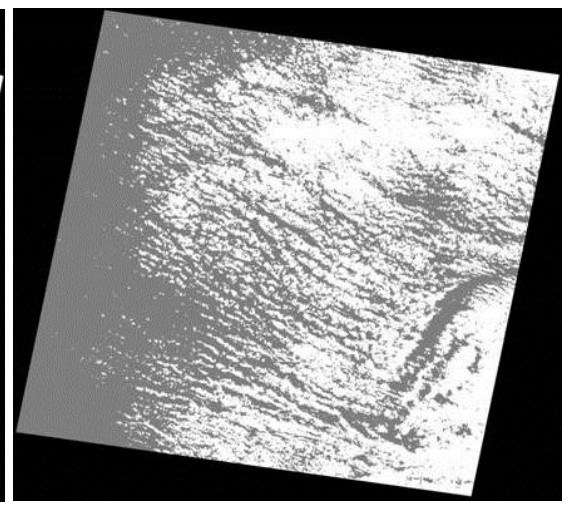

(b)

Figura 16: Máscaras de nuvem da cena 218/065. (a) Máscara gerada pelo classificador de nuvem; (b) Máscara de nuvem de referência.

A figura 17 apresenta os resultados da classificação de sombra de nuvem. A tabela 8 apresenta os percentuais calculados a partir da comparação das máscaras automática e de referência. $9.00 \%$ dos pixeis dessa cena são sombra de nuvem. $7.77 \%$ foram classificados com acerto e $1.23 \%$ erroneamente não foram classificados. A acurácia do classificador nesse caso foi de $86.33 \%$. A acurácia global da classificação foi de $94.77 \%$.

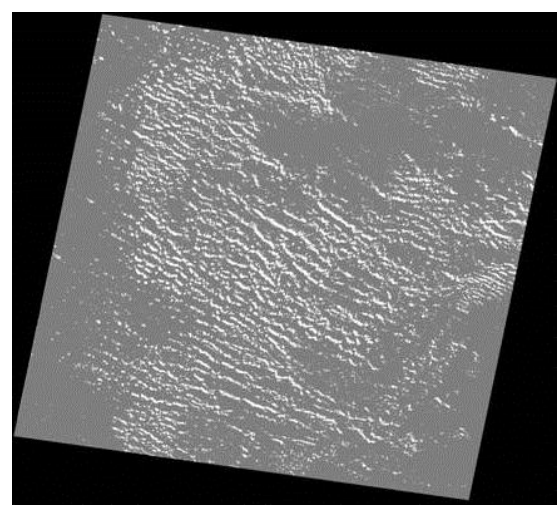

(a)

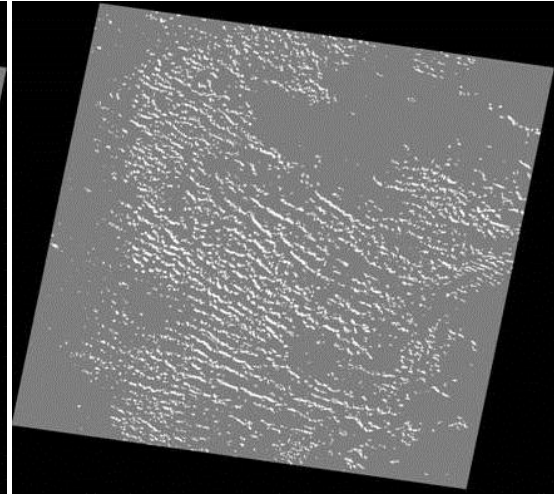

(b)

Figura 17: Máscaras de sombra de nuvem da cena 218/065. (a) Máscara gerada pelo classificador de sombra de nuvem; (b) Máscara de sombra de nuvem de referência.

Tabela 8: Resultados da classificação de sombra de nuvem da cena 218/065.

\begin{tabular}{l|l|c|c}
\hline $\begin{array}{l}\text { \% de pixeis classificados como } \\
\text { sombra de nuvem com acerto }\end{array}$ & $\begin{array}{c}\text { \% de pixeis não classificados } \\
\text { como sombra de nuvem com } \\
\text { acerto }\end{array}$ & $\begin{array}{c}\text { \% de } \\
\text { falsos } \\
\text { positivos }\end{array}$ & $\begin{array}{c}\text { \% de } \\
\text { falsos } \\
\text { negativos }\end{array}$ \\
\hline $7.77 \%$ & $87.00 \%$ & $4.00 \%$ & $1.23 \%$ \\
\hline
\end{tabular}




\section{Conclusões}

Nesse trabalho foi apresentada uma metodologia para a detecção automática de nuvem e sombra de nuvem em imagens de sensores que atuam na faixa do visível e do infravermelho próximo. $\mathrm{O}$ trabalho visa à detecção de nuvem e sombra de nuvem em imagens do sensor AWFI que estará a bordo do satélite AMAZONIA-1. Esse trabalho está inserido num problema maior que é a geração automática de mosaicos multitemporais livre de interferências por nuvem ou sombra de nuvem para imagens AWFI.

Na inexistência de imagens AMAZONIA-1 AWFI os testes foram conduzidos com imagens LANDSAT-5 TM. De uma forma geral, os resultados iniciais podem ser considerados satisfatórios. A acurácia média da classificação de nuvem foi de $88.70 \%$ e da classificação de sombra de nuvem de $75.03 \%$. A acurácia global da classificação foi de $92.73 \%$ para nuvem e 94.05\% para sombra de nuvem. Pode-se dizer então que mais de $90 \%$ dos pixeis das imagens foram interpretados e classificados como nuvem, não nuvem, sombra e não sombra corretamente.

Espera-se que os resultados obtidos com a classificação de sombra de nuvem sejam melhorados utilizando-se imagens de referências sazonais. Isso aumentaria a semelhança entre as imagens e a imagem diferença representaria melhor as diferenças provenientes de sombras de nuvens. Na classificação de nuvem verificou-se que o percentual de falsos positivos ficou em torno de $9 \% \mathrm{em}$ dois dos testes conduzidos. Isso pode ser atribuído à utilização de um buffer que dilata a área classificada. A eliminação desse buffer pode trazer melhores resultados.

Novos testes devem ser conduzidos considerando um conjunto maior de imagens.

\section{AGRADECIMENTOS}

Este trabalho foi desenvolvido como parte da execução de um contrato entre o INPE e a AMS Kepler celebrado segundo a Lei de Inovação Tecnológica.

Este trabalho é financiado parcialmente pelo processo número 2012/50407-7, Fundação de Amparo à Pesquisa do Estado de São Paulo (FAPESP).

\section{REFERÊNCIAS BIBLIOGRÁFICAS}

Candeias, A. L. B.; Silva, A. G. O. "Geração de Imagem Sintética com Menor Proporção de Nuvens a Partir de Imagens Multitemporais”. In: Anais do II Simpósio Brasileiro de Geomática e V Colóquio de Ciências Geodésicas, 24-27 Julho, Presidente Prudente, São Paulo, Brasil, p. 837842, 2007.

Champion, N. "Automatic cloud detection from multi-temporal satellite images: towards the use of Pléiades time series". In: International Archives of the Photogrammetry, Remote Sensing and Spatial Information Sciences, v. XXXIX-B3, 2012.

Irish, R. R. "LANDSAT 7 Automatic Cloud Cover Assessment". In: Proceedings of SPIE 4049, Algorithms for Multispectral, Hyperspectral, and Ultraspectral Imagery VI, v. 4049, p. 348-355, 2000.

Bol. Ciênc. Geod., sec. Artigos, Curitiba, v. 22, nํ2, p.336-388, abr - jun, 2016. 
Li, M.; Liew, S. C.; Kwoh, L. K. "Automated Production of Cloud-Free and Cloud Shadow-Free Image Mosaics From Cloudy Satellite Imagery". In: International Archives of the Photogrammetry, Remote Sensing and Spatial Information Sciences, v. XXXV-B3, p. 559-564, 2004.

Liporace, F. S., "Programação paralela com GPU aplicada ao registro automático de imagens de satélites”. In: Anais do XVI Simpósio Brasileiro de Sensoriamento Remoto, 13-18 Abril, Foz do Iguaçu, Paraná, Brasil, p. 5978-5985, 2013.

Polidorio, A. M.; Imai, N. N.; Tommaselli, A. M. G.; Flores, F. C. "Detecção e Discriminação de Sombras, Nuvens e Corpos D'Água em Imagens de Sensoriamento Remoto”. Revista Brasileira de Cartografia, n.58/03, p. 223-232, 2006.

Silva, W. A.; Imai, N. N.; Polidorio, A. M. "Validação de Nuvens e Sombras Detectadas em Imagens CCD/CBERS por Correlação de Pontos Candidatos". In: Anais do II Simpósio Brasileiro de Geomática e V Colóquio de Ciências Geodésicas, 24-27 Julho, Presidente Prudente, São Paulo, Brasil, p. 996-1002, 2007.

Song, M.; Civco, D. L. "A knowledge-based approach for reducing cloud and shadow". In: Proceedings of ASPRS-ACSM Annual Conference and FIG XXII Congress, April 22-26, 2002.

Zhu, Z.; Woodcock, C. E. "Object-based cloud and cloud shadow detection in LANDSAT imagery”. Remote Sensing of Environment, n. 118, p. 83-94, 2012.

Recebido em Maio de 2014.

Aceito em Outubro de 2015. 